\title{
Bayesian spatial modelling of childhood cancer incidence in Switzerland using exact point data: a nationwide study during 1985-2015
}

\author{
Garyfallos Konstantinoudis ${ }^{1,2^{*}}$, Dominic Schuhmacher ${ }^{3}$, Roland A. Ammann ${ }^{4}$, Tamara Diesch ${ }^{5}$, \\ Claudia E. Kuehni ${ }^{1}$, Ben D. Spycher ${ }^{1}$, for the Swiss Paediatric Oncology Group and the Swiss National Cohort \\ Study Group
}

\begin{abstract}
Background: The aetiology of most childhood cancers is largely unknown. Spatially varying environmental factors such as traffic-related air pollution, background radiation and agricultural pesticides might contribute to the development of childhood cancer. This study is the first investigation of the spatial disease mapping of childhood cancers using exact geocodes of place of residence.

Methods: We included 5947 children diagnosed with cancer in Switzerland during 1985-2015 at 0-15 years of age from the Swiss Childhood Cancer Registry. We modelled cancer risk using log-Gaussian Cox processes and indirect standardisation to adjust for age and year of diagnosis. We examined whether the spatial variation of risk can be explained by modelled ambient air concentration of $\mathrm{NO}_{2}$, modelled exposure to background ionising radiation, areabased socio-economic position (SEP), linguistic region, duration in years of general cancer registration in the canton or degree of urbanisation.

Results: For all childhood cancers combined, the posterior median relative risk (RR), compared to the national level, varied by location from 0.83 to 1.13 (min to max). Corresponding ranges were 0.96 to 1.09 for leukaemia, 0.90 to 1.13 for lymphoma, and 0.82 to 1.23 for central nervous system (CNS) tumours. The covariates considered explained $72 \%$ of the observed spatial variation for all cancers, $81 \%$ for leukaemia, $82 \%$ for lymphoma and $64 \%$ for CNS tumours. There was weak evidence of an association of CNS tumour incidence with modelled exposure to background ionising radiation (RR per SD difference $1.17 ; 0.98-1.40)$ and with SEP $(1.6 ; 1.00-1.13)$.
\end{abstract}

Conclusion: Of the investigated diagnostic groups, childhood CNS tumours showed the largest spatial variation. The selected covariates only partially explained the observed variation of CNS tumours suggesting that other environmental factors also play a role.

Keywords: Cancer clusters, Central nervous system cancer, Childhood cancer, Bayesian spatial modelling, Point processes

*Correspondence: g.konstantinoudis@imperial.ac.uk

${ }^{2}$ Epidemiology and Biostatistics Department, School of Public Health, Imperial College London, London, UK

Full list of author information is available at the end of the article

\section{Background}

The causes of childhood cancers are poorly understood. Epidemiological research on the atomic bomb survivors indicated that ionising radiation in high doses can cause

c) The Author(s) 2020. This article is licensed under a Creative Commons Attribution 4.0 International License, which permits use, sharing, adaptation, distribution and reproduction in any medium or format, as long as you give appropriate credit to the original author(s) and the source, provide a link to the Creative Commons licence, and indicate if changes were made. The images or other third party material in this article are included in the article's Creative Commons licence, unless indicated otherwise in a credit line to the material. If material is not included in the article's Creative Commons licence and your intended use is not permitted by statutory regulation or exceeds the permitted use, you will need to obtain permission directly from the copyright holder. To view a copy of this licence, visit http://creativeco mmons.org/licenses/by/4.0/. The Creative Commons Public Domain Dedication waiver (http://creativecommons.org/publicdomain/ zero/1.0/) applies to the data made available in this article, unless otherwise stated in a credit line to the data. 
childhood leukaemia and central nervous system (CNS) tumours [1, 2]. A number of environmental factors have been suggested that could partially explain cancer risks in the general population, including traffic-related air pollution [3], background radiation [2, 4] and agricultural pesticides [5]. These risk factors vary in space and it is thus natural to expect spatial variation in childhood cancer incidence. Conversely, investigating the spatial variation of childhood cancer incidence might help generate new hypotheses about environmental risk and identify areas of potential environmental contamination.

Disease mapping is a common way of capturing the spatial variation of a disease. Direct estimation of disease incidence in small areas is subject to large sampling variability, particularly for rare diseases. Disease mapping mitigates this problem by exploiting spatial correlation between neighbouring areas and smoothing small area rates based on neighbouring values [6]. Several previous studies have investigated spatial variation in childhood cancer risk using disease mapping. Studies focusing on childhood leukaemia reported evidence of spatial variation in Ohio, USA [7], Texas, USA [8], Yorkshire, UK [9], but not in France [10]. The study in Texas also examined childhood lymphomas and reported some evidence of spatial variation of Hodgkin lymphoma [8]. A study in Kenya reported evidence of spatial variation of Burkitt's lymphoma with higher rates in the northern part of the country [11]. A study in Florida, USA, focusing on childhood brain tumours reported some evidence of high excess risk in several non-adjacent counties [12].

The different findings regarding spatial variation of childhood cancers might reflect differences between the countries or methodological limitations. Most previous studies relied on areal data (data aggregated on administrative units) $[8-10,12-14]$. Results from such studies depend on spatial unit selected, which is referred to as the Modifiable Areal Unit Problem [15]. Furthermore, associations between cancer incidence and environmental factors assessed at group level may be subject to ecological fallacy, i.e. they may not correctly reflect underlying associations at the individual level [16]. In a simulation study, we showed that spatial modelling based on exact geocodes is more accurately identifies areas of higher risk compared to traditional disease mapping based on count data aggregated to small administrative areas [17]. To the best of our knowledge, only one previous study used precise geocodes, but the authors did not attempt to explain the observed variation of childhood leukaemia risk by incorporating environmental exposures in the model [7]. Lastly, all the previous studies used geographical information about the place of diagnosis of the cancer cases. Children may be more susceptible to certain environmental exposures early in life and thus location of residence at birth may be more relevant [18].

In this nationwide study, we investigated the spatial variation of childhood cancers in Switzerland using precise locations of residence. We performed analysis using place of birth and diagnosis. We focused on the following main diagnostic groups: all childhood cancers, childhood leukaemia, lymphoma and CNS tumours and assessed the extent to which selected covariates could explain the observed spatial variation.

\section{Methods}

\section{Study population}

We retrieved children diagnosed with cancer in Switzerland during 1985-2015 at age 0-15 from the Swiss Childhood Cancer Registry (SCCR). SCCR is a nationwide registry with high completeness. Estimates suggest that it includes $91 \%$ of all incident cases for the period 1985-2009 and >95\% for 1995-2009 [19]. It collects residential addresses from time of diagnosis back to birth. The addresses were geocoded according to the Swiss grid coordinate system using a combination of different sources of georeferenced building addresses including the Swiss postal system, the geoportal maintained by the Federal Office of Topography (swisstopo; http://map.geo. admin.ch), and Google Maps. We wrote an R function to assign a pair of geocodes to every address (https://githu b.com/gkonstantinoudis/GeoSwiss) based on these data sources. Geocodes that could not be identified by this procedure where manually searched using the mentioned web sites. If the available address information was incomplete (e.g. only street without number, or only postal code without street), approximated geocodes were assigned (e.g. a central location on the street, or of the municipality). We classified cases based on the margin of error 1 $(<50 \mathrm{~m}), 2(>50 \mathrm{~m}$ and $<100 \mathrm{~m}), 3(>100 \mathrm{~m}$ and $<500 \mathrm{~m})$ and $4(>500 \mathrm{~m})$. For $94 \%$ of the cases, we geocoded residential addresses with a margin of error $<100 \mathrm{~m}$.

Population data was available through the Swiss National Cohort (SNC) which includes exact geocoded residential locations of all Swiss residents at the times of censuses (1990, 2000 and 2010-2015). To calculate population at risk by age group, year and spatial unit $\left(1 \mathrm{~km}^{2}\right.$ grid cell or municipality), we performed linear interpolation of age, year and spatial unit specific weights, see Additional file 1: Text S1 and Figures S1, S2. The $1 \mathrm{~km}^{2}$ grid size was selected as a compromise between our goal of high precision maps on the one hand, and data confidentiality considerations and reduction of computational burden on the other. We then performed indirect standardisation by calculating the expected number of cases adjusted by age and year: Let $q_{i, j}$ be the nationwide cancer incidence rate and $P_{i, j, k}$ the population counts 
with subscript referring to the $i$-th age group $(0-4,5-9$, 10-15), $j$-th year (1985-2015), and $k$-th spatial unit (grid cell, or municipality). Then the expected number of cases in the $k$-th spatial unit is:

$$
E_{k}=\sum_{i} \sum_{j} q_{i, j} \cdot P_{i, j, k} .
$$

To calculate the expected number of cases for the analysis based on the location at birth we used a similar procedure restricting to children aged $<1$ year at census:

$$
E_{k}=\sum_{j} q_{0, j} \cdot P_{0, j, k}
$$

where the age index $i=0$ represents children aged $<1$ year. We repeated the aforementioned procedures for the different diagnostic groups. For more information refer to Additional file 1: Text S1.

\section{Outcomes}

The SCCR classifies diagnoses according to the International Classification of Childhood Cancers Third Edition (ICCC3). We examined all childhood cancers combined (ICCC3 main groups I-XII) and then separately childhood leukaemia (ICCC3 main group I), lymphoma (ICCC3 main group II) and CNS tumours (ICCC3 main group III). We focused on the main diagnostic groups because of the larger sample size.

\section{Covariates}

As potential explanatory variables, we included predicted ambient air concentration of $\mathrm{NO}_{2}$, predicted total dose rate from terrestrial gamma and cosmic radiation, neighbourhood-level socio-economic position (SwissSEP for the year 2001) [20], years of general cancer registration in the canton, language region and the degree of urbanisation as covariates (Additional file 1: Table S1 and Figures S3-S8). Traffic-related air pollution and total background radiation were previously found to be associated with childhood cancer risks in Switzerland [21, 22]. We included SEP, linguistic region and degree of urbanisation to account for regional, socio-economic and socio-cultural differences. We included years of cantonal cancer registration to account for heterogeneous registry completeness. The SCCR records childhood cancer cases treated in one of the nine specialised paediatric oncology (SPOG) clinics and complements the registry with any additional cases recorded by the cantonal registries. Some cantons already had a cancer registry at the beginning of our study period, others established one during the study period and others after the end of the study. For cantons with more years of general registration, we thus expect the "apparent" childhood cancer incidence over the study period to be slightly higher.

\section{Statistical analysis}

We used log-Gaussian Cox processes (LGCPs) to model locations of incident cancer cases [23]. The point process assumed to generate the case locations is an inhomogeneous Poisson process with random intensity $e(s) r(s), s \in W$, where $e(s)$ denotes the intensity of the expected number of cases (approximated with $E_{k}$ ), $r(s)$ the risk and $W$ denotes the observation window (Switzerland in our case). We model the continuous logrisk surface $\log r(s), s \in W$, via a spatial mixed effects model $\boldsymbol{X}(s) \boldsymbol{\beta}+Z(s)$, where the first summand adjusts for covariate effects and the second summand models the spatial variation. The process $Z(s)$ is assumed to be a zero mean Gaussian random field (GRF) with Matérn covariance function. We fix the smoothness parameter $v$ to 1 , which is common practice to alleviate the computational burden [24]. The Gaussian field is then controlled by two parameters: a variance parameter $\sigma^{2}$ and a range parameter $\rho$ (roughly, the distance between $s$ and $t$ in $W$ at which the correlation between the values $Z(s)$ and $Z(t)$ of the field falls below 0.10$)$. To be avoid large dense covariance matrices, we use the approach by Lindgren et al. [25]. Thus, we approximate the field $Z(s), s \in W$, by a finite element representation of the (weak) solution of a certain stochastic partial differential equation (SPDE):

$$
Z(s) \approx \sum_{i=1}^{M} \psi_{i}(s) Z_{i}=: Z_{*}(s),
$$

where $M$ denotes the total number of nodes in an underlying triangulation of $W, \psi_{i}$ are piecewise linear basis functions taking the value 1 at the $i$-th node and 0 at every other node, and $Z_{i}$ are random weights forming a (finitely indexed) Gaussian Markov random field (GMRF) $Z=\left(Z_{i}\right)_{i=1, \ldots, M}$. The latter has a sparse precision matrix $\boldsymbol{Q}(\rho, \sigma)$. We used penalised complexity priors (PC priors) for the hyperparameters $\sigma$ and $\rho$. For the construction of these priors in the present GRF setting, see [26]. The full model specification then reads:

$$
\begin{aligned}
& \log r(s)=X(s) \boldsymbol{\beta}+Z_{*}(s) \\
& \boldsymbol{Z} \sim N\left(0, \boldsymbol{Q}(\rho, \sigma)^{-1}\right) \\
& \boldsymbol{\beta} \sim N(0,10 \boldsymbol{I}) \\
& \sigma \sim \operatorname{PCprior}(0.01,1)
\end{aligned}
$$




$$
\rho \sim \operatorname{PCprior}(0.5,60)
$$

where $\boldsymbol{X}(s)=\left(X_{0}(s), X_{1}(s), \ldots, X_{l}(s)\right)$ is a row vector of spatial covariates and $I$ is the identity matrix. The userdefined scale of the PC prior of the standard deviation $\sigma$ was chosen such that the variance of the log relative risk at any fixed location exceeds 1 with probability 0.01 . The scale for the range parameter $\rho$ was adjusted so that the probability of having range smaller than $60 \mathrm{~km}$ is 0.50 . We used the Integrated Nested Laplace Approximation (INLA) to render Bayesian analysis for the above model computationally feasible $[27,28]$.

We computed maps of posterior median (unadjusted or adjusted for the covariates) of spatial relative risk (RR, i.e. $\exp \{Z(s)\})$ compared to national level on a $1 \times 1 \mathrm{~km}^{2}$ grid. We also mapped exceedance probabilities defined as the posterior probability, in each grid cell, that RR exceeds 1 . The fixed effects $\beta_{i}$ (log-relative-risk per unit increase in the covariate) are reported as posterior median of RR, i.e. $\exp \left\{\beta_{i}\right\}$, and $95 \%$ credibility intervals $(\mathrm{CI})$. The continuous variables $\mathrm{NO}_{2}$, ionizing radiation, SEP and years of cantonal cancer registration were scaled and thus $\exp \left\{\beta_{i}\right\}$ is interpreted as the multiplicative change of the risk at a fixed location when the covariate is increased by 1 standard deviation (SD). They were included as linear terms since there was no indication for a more complex model (Additional file 1: Figure S9). Henceforth, the model adjusted for the aforementioned covariates is referred to as the adjusted model, whereas the model without covariates as the unadjusted. Both adjusted and unadjusted models were standardised for population, age and year of diagnosis by including the expected number of cases as an offset in the model (Additional file 1: Text S1, S2).

We also report the percentage of variance explained by the selected risk factors by evaluating median and 95\% CI of the posterior of an extension of Bayesian $R^{2}$ [29]:

$$
R^{2}=\frac{V(\boldsymbol{X}(s) \boldsymbol{\beta})}{V(\boldsymbol{X}(s) \boldsymbol{\beta})+V(Z(s))},
$$

where $V(\cdot)$ denotes the variance over the $K$ spatial units, $\boldsymbol{\beta}$ is the vector of intercept and covariates and $\boldsymbol{X}(s)$ is the design matrix. We calculated $R^{2}$ for the fully adjusted model, a model including all selected covariates except years of cantonal cancer registration (we refer to this set of covariates as 'putative risk factors'), and the univariable model including only years of cantonal cancer registration. This allowed us to distinguish spatial variation explained purely by the degree of completeness of registration from variation explained by covariates that might reflect aetiological factors (putative risk factors). For consistency with the literature, we also fitted the BesagYork-Mollié (BYM) model using disease counts per municipality, for more information see [26, 30,31] and Additional file 1: Text S2

\section{Sensitivity analysis}

We ran a sensitivity analysis to examine the robustness of the results with respect to different scalings of the penalized complexity priors for the range parameter of the latent field [26], with median range fixed at 1, 10, 60, 120 and $240 \mathrm{~km}$.

\section{Results}

\section{Study population}

We identified 5969 cases with childhood cancer during 1985-2015 in Switzerland. We excluded 22 (0.3\%) cases without available geocode of residence at diagnosis. Of the included 5947 children, 32\% $(\mathrm{N}=1880)$ had leukemia, $13 \%(\mathrm{~N}=772)$ lymphoma and $22 \%(\mathrm{~N}=1290)$ a CNS tumor. For the analysis using location at birth we first excluded 1194 cases born before 1985 and then 577 additional cases with no geocode at birth yielding 4198 cases for the analysis (Table 1). Of the excluded cases for this analysis, 342 were born abroad, 114 were born in Switzerland but no address was recorded, while for 121 the country of birth was missing. The age and sex distribution follows similar patterns as in neighbouring countries (Table 1) [32, 33].

\section{Spatial analysis}

We found evidence of spatial variation for all cancers combined and CNS tumours at diagnosis, Fig. 1, Table 2

\begin{tabular}{|c|c|c|c|c|c|c|}
\hline & \multicolumn{3}{|l|}{ Birth } & \multicolumn{3}{|l|}{ Diagnosis } \\
\hline & Total N (\%) & Female N (\%) & $\begin{array}{l}\text { Median age } \\
\text { at diagnosis }\end{array}$ & Total N (\%) & Female N (\%) & $\begin{array}{l}\text { Median age } \\
\text { at diagnosis }\end{array}$ \\
\hline All cancers & 4198 (100) & $1875(45)$ & 4.8 & $5947(100)$ & $2654(45)$ & 6.4 \\
\hline Leukaemia & $1384(33)$ & $570(41)$ & 4.2 & $1880(32)$ & $781(42)$ & 4.9 \\
\hline Lymphoma & $459(11)$ & $161(35)$ & 10.2 & $772(13)$ & $279(36)$ & 11.5 \\
\hline CNS tumours & $902(21)$ & $421(47)$ & 6.0 & $1290(22)$ & $590(456)$ & 7.1 \\
\hline
\end{tabular}

Table 1 Number of cases and median age at diagnosis for the analysis based on the location at birth and diagnosis 


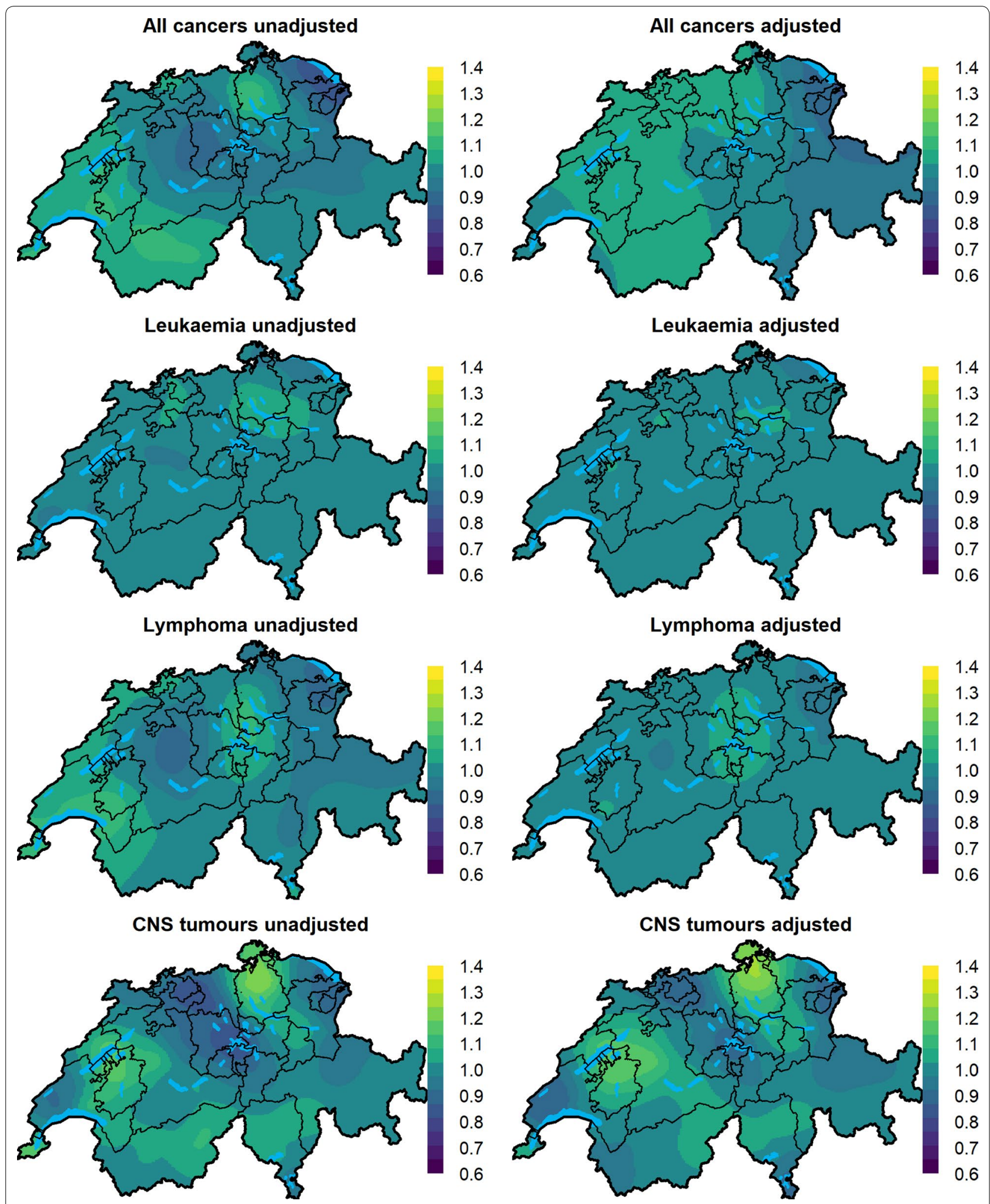

Fig. 1 Maps of the median prosterior of the spatial relative risk for different cancer types during 1985-2015 in Switzerland. The adjusted models are models adjusted for predicted ambient $\mathrm{NO}_{2}$ concentration, predicted dose rate from terrestrial gamma and cosmic radiation, SEP, years of existing general cancer registry in the canton, language region and level of urbanisation 


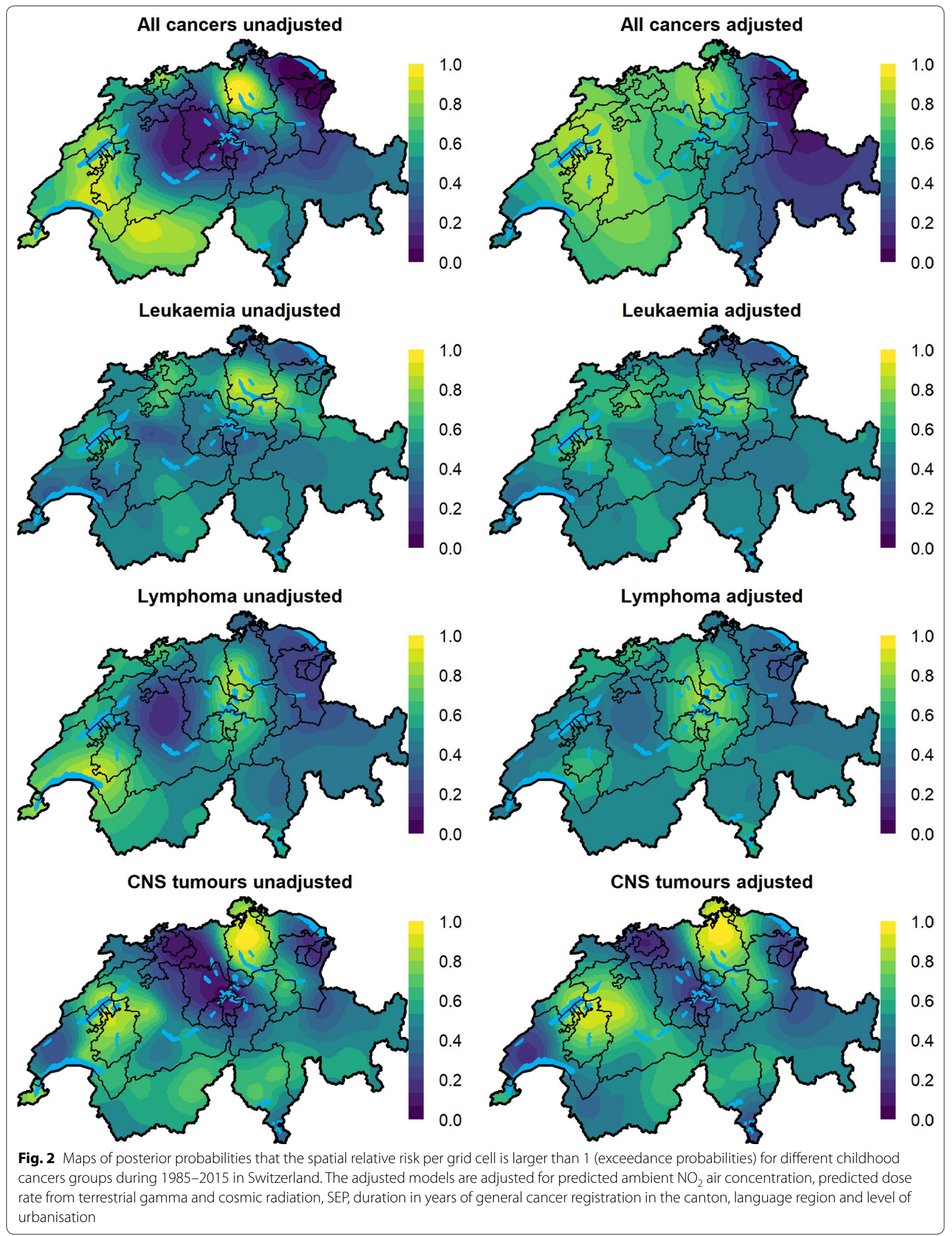



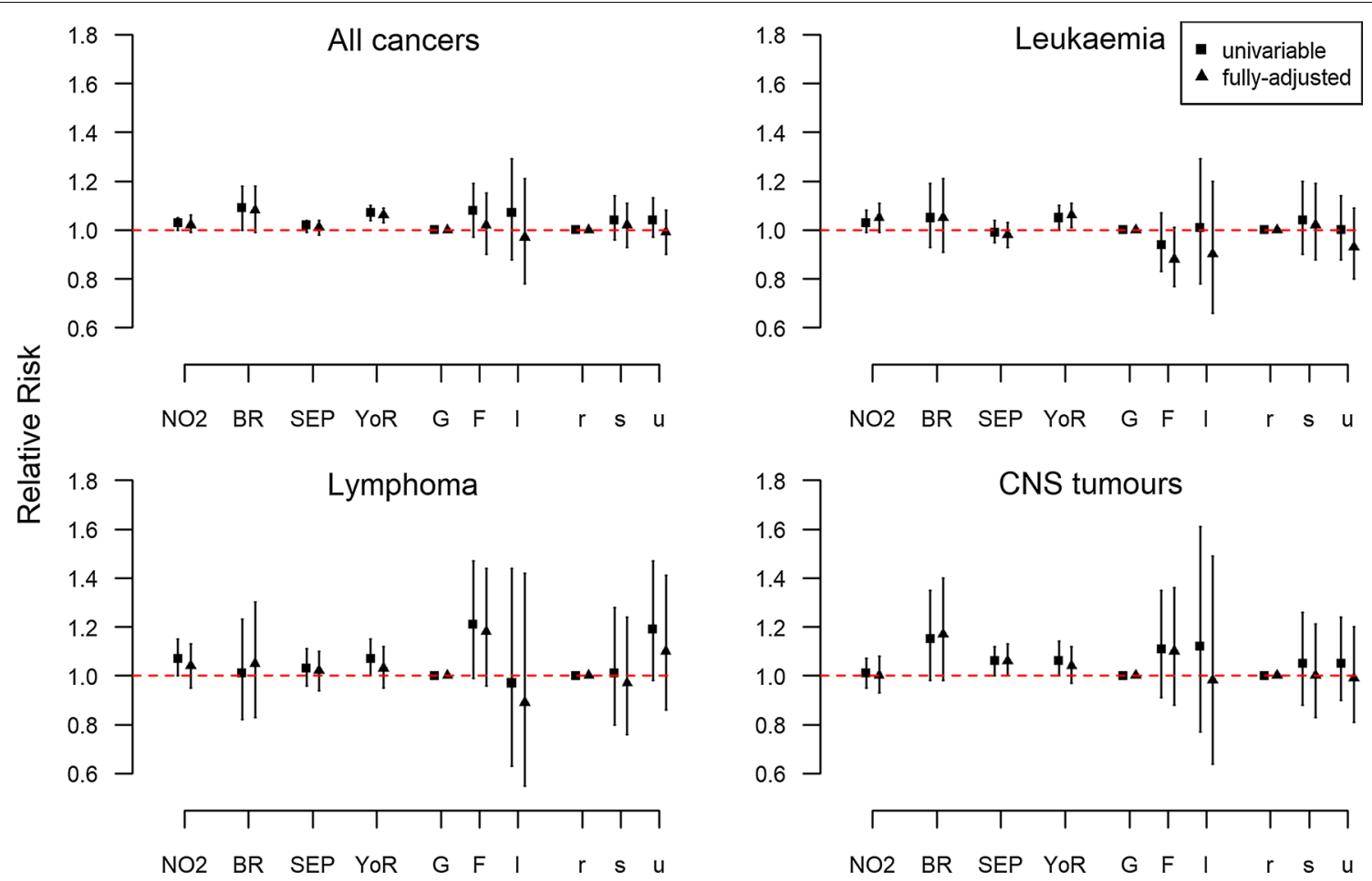

Fig. 3 Univariable and fully adjusted regression analysis at time of diagnosis. The fixed effects are summarized using the posterior median of the relative risk together with $95 \%$ credibility regions. $\mathrm{NO}_{2}$ nitrogen dioxide, CNS Central Nervous System tumours, BR total dose background radiation, SEP socio-economic position, YOR years of existing cantonal registry, G German speaking part, $F$ French speaking part, / Italian speaking part, $r$ rural areas, $s$ semi-urban areas, $u$ urban areas. Predicted ambient $\mathrm{NO}_{2}$ air concentration, predicted background ionising radiation, SEP and duration in years of general cancer registration in the canton were scaled so that the standard deviations (SD) are 1 and considered as linear effects. Their interpretation is a multiplicative increase (or decrease) in the number of observed cases compared to the number of the expected cases per 1 SD increase (or decrease) in the covariate. The sd for predicted ambient $\mathrm{NO}_{2}$ air concentration is $77.7 \mu \mathrm{g} / \mathrm{m}^{3} \times 10$, for predicted background ionising radiation $60.2 \mathrm{nSv} / \mathrm{h}$, for SEP 8.7 units and for duration in years of general cancer registration in the canton 11.6 years. The fully-adjusted models are models adjusted for predicted ambient $\mathrm{NO}_{2}$ air concentration, predicted dose rate from terrestrial gamma and cosmic radiation, SEP, duration in years of general cancer registration in the canton, language region and level of urbanisation

We also examined the spatial variation of childhood cancers using place of birth. The spatial variation of cancer risks was generally smaller but the spatial patterns were largely consistent with the results for diagnosis (Additional file 1: Figures S10-S11 and Tables S3, S5).

We also examined the spatial variation using the BYM model. The maps and variation of median posterior RR were similar to the ones obtained by LGCPs, Additional file 1: Figures S10-S15. The estimates of the fixed effects were in the same direction but tended to be somewhat weaker than in the LGCP models (Additional file 1: Tables S4-S7).

\section{Sensitivity analysis}

The resulting maps and effect estimates varied only little when using different priors for the hyperparameters, Additional file 1: Figures S16-S25.

\section{Post-hoc analysis}

Given the larger spatial variation in the risk of CNS tumours we ran several post hoc analyses for this diagnostic group. First, we restricted the analysis to place of diagnosis for the period of 1995-2015 $(\mathrm{n}=968)$, in which the coverage is highest (>95\%). The resulting spatial pattern was closely similar to the main analysis (Additional file 1: Figure S26). Second, we wanted to identify if the observed variation of CNS tumour was specific to particular diagnostic subgroups. We reran the analysis for place at diagnosis for astrocytoma (IIIb, $n=511$ cases), intracranial and intraspinal embryonal tumours (IIIc, $\mathrm{n}=266$ ) and other CNS (IIIa, IIId-f, $\mathrm{n}=512$ ), following the classification used in our previous analysis of spatial clustering of childhood cancers in Switzerland [17]. We found that intracranial and intraspinal embryonal tumours showed the highest spatial variation with the median posteriors RR varying from 0.74 to 1.59 ( $\mathrm{min}$ to $\max$ ) in the unadjusted and 0.74 to 1.38 in the adjusted 
model, Additional file 1: Figure S27. However, the areas highlighted in Figs. 1, 2 stand out in all CNS subgroups Additional file 1: Figures S27, S28. Lastly, we hypothesized that differences in diagnostic practices between the nine SPOG clinics may explain the apparent spatial variation of CNS tumour risks. We thus constructed a spatial covariate reflecting the catchment areas of the different SPOG centres. Including an additional random effect to adjust for these catchment areas only slightly reduced the unexplained spatial variation. The spatial pattern of relative risk remained largely unchanged (Additional file 1: Text S3 includes the analysis and figures).

\section{Discussion}

\section{Main findings}

This nationwide study based on precise locations of residence sheds new light on the spatial variation of childhood cancer incidence in Switzerland and the extent to which this variation can be explained by environmental exposures and other spatial covariates. The spatial variation of cancer risk was small for childhood leukaemia and lymphoma and mostly explained by covariates. That of CNS tumours, particularly intracranial and intraspinal embryonal tumours, was larger and persisted after adjustment for covariates. Duration of general cancer registration in the canton was associated with higher observed cancer risk. Other covariates associated with cancer incidence included predicted ambient air concentration of $\mathrm{NO}_{2}$ for all cancers, lymphoma and leukaemia and SEP and modelled dose rates from terrestrial gamma and cosmic background radiation for CNS tumours and all cancers.

\section{Comparison of our study with other spatial analyses of childhood cancer risks}

Compared to other studies that have investigated the spatial distribution of childhood cancers, our study stands out in that it uses precise geocoded place of residence and attempts to explain any spatial variation with commonly discussed putative environmental risk factors and completeness of registration. Our study is comparable with studies that performed parametric disease mapping, and in the lack of other studies that used LGCPs, with the previous studies that investigated the spatial variation of childhood leukaemia risks using areal data and BYM models in France [10], Yorkshire, UK [9] and in Florida, USA [12]. A study in France on acute leukaemia reported no evidence of spatial variation in the incidence of acute leukaemia at the département level [10]. A study in Yorkshire using data aggregated on the electoral ward level reported higher childhood leukaemia risks in the less populated county of North Yorkshire [9]. We did not observe higher leukaemia risk in less populated areas. Our results are in agreement with a study in Florida that reported evidence of spatial variation of brain tumours for cases 0-19 years old [12].

Other studies examining the spatial distribution of childhood cancer have focused on extra-Poisson variation and spatial clustering [34]. The general picture shows mixed results for childhood leukaemia and weak or no evidence of spatial clustering of lymphoma and CNS tumours [35-37]. In previous studies using the same data, we found no evidence of clustering of childhood cancers, leukaemia, lymphoma or CNS tumours, but weak evidence, consistent with the literature, for Hodgkin lymphoma and embryonal CNS tumours [38, 39]. We observed a cluster of intracranial and intraspinal CNS tumours in the French speaking part of Switzerland consistent with the pattern observed for CNS tumours in the present study [38].

\section{Comparison of our study with other studies on environmental risk factors of childhood cancer}

The observed spatial associations between childhood cancer risks and putative risk factors are in broad agreement with other studies that have investigated these associations disregarding the spatial context.

Of the included covariates in the current study, predicted ambient $\mathrm{NO}_{2}$ air concentration showed the strongest spatial association with childhood leukaemia risks. There is increasing evidence of a link between traffic related air pollution and childhood cancers, in particular childhood leukaemia [40]. In recent metaanalyses associations with leukaemia risks were strongest for exposure to benzene and weaker for $\mathrm{NO}_{2}$ [3]. Using partly overlapping data, we reported an increased risk of leukaemia among children living less than $100 \mathrm{~m}$ from a highway [21].

Previous studies investigating childhood cancer risks in relation to background ionising radiation showed mixed results [22, 41-44]. While two studies reported associations between childhood leukaemia and gamma radiation [22, 41], others found no evidence of an association [42-44]. Using partly overlapping data, we previously reported evidence of associations with gamma radiation for both childhood leukaemia and CNS tumours [22]. In the current study the association was largest for all cancers and CNS tumours. The evidence from other studies examining the effect of gamma radiation on the risks of CNS tumours in children was weak $[41,43]$.

Our study found weak evidence of a potential association between SEP and CNS tumours. Previous studies in Switzerland have reported weak association between socioeconomic status and childhood leukaemia incidence, but a strong effect for CNS survival $[45,46]$. Our 
results are consistent with a large UK case-control study which reported increased risk of CNS tumours in higher social classes [47]. A recent study in Spain also reported a positive association between risk of CNS tumours and socioeconomic status [48]. In contrast, a study in NorthWest England [49] and a study from Norway [50] found no evidence of an association between CNS tumours and measures of socio-economic status.

\section{Strengths and limitations}

To the best of our knowledge this is the first study attempting to model and explain the spatial distribution of childhood cancers using precise locations of residence. We used LGCPs, which represent the current state of the art for modelling such point data of disease incidence and, as we have recently shown, outperform traditional methods in identifying high risk areas [17]. These models allowed us to incorporate spatial covariates and quantify their contribution to explaining the observed spatial variation. We also tried to disentangle variation attributed to registration completeness from variation due to putative risk factors. Furthermore, in contrast to previous studies, we examined both place of birth and diagnosis. Although results were closely similar, this comparison could potentially have revealed differences in time windows of susceptibility to different risk factors. The population at risk was retrieved from national censuses and cases from a nationwide registry with high completeness [19]. We attempted to correct for potential selection bias due to regional differences in case ascertainment by including duration of general cancer registration in the canton and, in post hoc analysis, SPOG centre catchment areas.

Due to data availability, we could not include all potential environmental risk factors discussed in the literature, for instance pesticide exposure. Furthermore, the spatial covariates included are subject to measurement errors and do not perfectly capture the spatial variation of residential exposures. We had little information about the magnitude of measurement errors, making it hard to propagate it in our modelling framework. Although we partly adjusted for differences in registration coverage, there may still be differences unaccounted for by our analyses. Our analysis is purely spatial and disregards and temporal or spatiotemporal variation. In contrast with previous work, which focused on spatiotemporal clustering [51], we focused on identifying spatial patterns that remain stable over comparably long time periods. Such patterns potentially reflect stationary sources of relevant environmental exposures. We implicitly adjusted for the national time trends of childhood cancers using a time varying offset. But our analysis ignores any temporal or spatiotemporal trends of the selected covariates (e.g. $\mathrm{NO}_{2}$ ). This may have diluted their effects and biased the estimated coefficients towards the null. Such bias may have particularly affected estimates for traffic related air pollution, as $\mathrm{NO}_{2}$ concentration decreased considerably during the study period while other covariates including, SEP, urbanisation and background radiation were relatively stable. Potential avenues of future research include extending this analysis to incorporate full spatiotemporal risk factors and interactions.

\section{Interpretation of findings}

Although the overall completeness of SCCR is larger than $95 \%$ after the mid-90s [19], we found that duration of general cancer registration in the canton can influence the apparent spatial variation of childhood cancers based on data from SCCR. This suggests that there are regional differences in registration completeness, which should be accounted for in future aetiological studies in Switzerland.

Our results are suggestive of an environmental aetiology for childhood CNS tumours and of aetiological differences between their histological subtypes. In post hoc analyses, the observed spatial variation was not fully explained by differences in cancer registration in the early years of the SCCR as it persisted in the more recent periods. Neither did differences between SPOG centres, for instance in ascertainment practices, explain the spatial variation. Unmeasured environmental risk factors are thus a likely explanation of the observed spatial variation. Possibly, spatial differences in the prevalence of genetic syndromes associated with these tumours might also partially explain the observed variation. In future research, there should be increased attention on putative environmental risk factors of CNS tumours, including SEP, background radiation and pesticide exposure (which was not accounted for in our analyses).

Our analysis shows that, locally, risks for childhood cancer in Switzerland can deviate from the national level by up to $13 \%$ (range of RR: $0.83-1.13$ ). These deviations tend to be smaller (0.96-1.09) for childhood leukaemia, in which case they appear to be largely explained by spatial covariates included in analysis. In contrast, for CNS tumours these variations are larger $(0.82-1.23)$ and to a lesser extent explained by included covariates. Adjustments for potential regional differences in registration or diagnostic practices did materially reduce this variability. If indeed this variation was caused by environmental factors, similar regional variation is to be expected in other countries. While our analysis could not identify the source of this variation, it does suggest that environmental factors other than background radiation and traffic related pollution is driving geographic variation in childhood CNS tumour incidence. Future research should therefore focus on investigating the environmental 
aetiology of CNS tumours. Such research could benefit from separate analysis of histological subtypes and the pooling of data across different studies to increase statistical power.

\section{Conclusion}

This study provides evidence of spatial differences in the incidence of childhood CNS tumours in Switzerland that could be partially explained by variations in socioeconomic factors and natural background radiation. The spatial variation of the risks for childhood leukaemia and lymphoma was smaller and mostly explained by measured covariates. Our study provides further support for an environmental aetiology for childhood CNS tumours, highlighting the need for future studies to distinguish between histologic subtypes.

\section{Supplementary information}

Supplementary information accompanies this paper at https://doi. org/10.1186/s12942-020-00211-7.

Additional file 1. Supplementary text, tables and figures supporting the main manuscript.

\section{Abbreviations}

CNS: Central nervous system; SCCR: Swiss childhood cancer registry; SNC: Swiss national cohort; ICCC3: International classification of childhood cancers 3rd edition; $\mathrm{NO}_{2}$ : Nitrogen dioxide; SEP: Socioeconomic position; SPOG: Swiss paediatric oncology group; LGCP: Log-Gaussian Cox process; RR: Relative risk; SD: Standard deviation; BYM: Besag-York-Mollié.

\section{Acknowledgements}

The work of the Swiss Childhood Cancer Registry is supported by the Swiss Paediatric Oncology Group (http://www.spog.ch), Schweizerische Konferenz der kantonalen Gesundheitsdirektorinnen und-direktoren (http://www. gdk-cds.ch), Swiss Cancer Research (http://www.krebsforschung.ch), Kinderkrebshilfe Schweiz (http://www.kinderkrebshilfe.ch), Ernst-Göhner Stiftung, Stiftung Domarena and National Institute of Cancer Epidemiology and Registration (http://www.nicer.org).

We thank the Swiss Federal Statistical Office for providing mortality and census data and for the support which made the Swiss National Cohort and this study possible. This work was supported by the Swiss National Science Foundation (grant nos. 3347CO-108806, 33CS30_134273 and 33CS30_148415).

\section{Member of study groups}

The members of the Swiss Pediatric Oncology Group Scientific Committee: R A Ammann (Bern), K Scheinemann (Aarau), M Ansari (Geneva), M Beck Popovic(Lausanne), P Brazzola (Bellinzona), J Greiner (St. Gallen), M Grotzer (Zurich), H Hengartner (St Gallen), T Kuehne (Basel), J Rössler (Bern), F Niggli

(Zurich), F Schilling (Lucerne), N von der Weid (Basel)

The members of the Swiss National Cohort Study Group:

Matthias Egger (Chairman of the Executive Board), Adrian Spoerri and Marcel Zwahlen (all Bern), Milo Puhan (Chairman of the Scientific Board), Matthias Bopp (both Zurich), Martin Röösli (Basel), Murielle Bochud (Lausanne) and Michel Oris (Geneva).

\section{Authors' contributions}

Conceptualisation: GK, BDS; Methodology: GK, DS, BDS; Formal analysis: GK; Validation: BDS, DS, CEK, RAA and TD; Writing —original draft: GK; Writing - review and editing: GK, DS, TD, RAA, CEK and BDS; Resources: CEK, TD, RAA, BDS; Supervision: DS and BDS. All authors read and approved the final manuscript.

\section{Funding}

This work was supported by Swiss Cancer Research (4012-08-2016, 3515-082014, 3049-08-2012), the Swiss Federal Office of Public Health (08.001616), the Swiss Cancer League (4592-08-2018, 02224-03-2008) and the Swiss National Science Foundation (320030_176218, PZ00P3_147987).

\section{Availability of data and materials}

The Swiss Childhood Cancer Registry is the permanent repository of data on childhood cancer cases used in this study. This data cannot be made publicly available for both legal and ethical reasons as this would compromise patient confidentiality and participant privacy. Interested researchers may contact the corresponding author or the Swiss Childhood Cancer Registry (http://child hoodcancerregistry.ch/) via its online contact form for further information.

\section{Ethics approval and consent to participate}

Ethics approval was granted through the Ethics Committee of the Canton of Bern to the SCCR on the 22th of July 2014 (KEK-BE: 166/2014).

\section{Consent of publication}

Not applicable

\section{Competing interests}

The authors declare that they have no competing interests.

\section{Author details}

${ }^{1}$ Institute of Social and Preventive Medicine (ISPM), University of Bern, Bern, Switzerland. ${ }^{2}$ Epidemiology and Biostatistics Department, School of Public Health, Imperial College London, London, UK. ${ }^{3}$ Institute for Mathematical Stochastics, University of Göttingen, Göttingen, Germany. ${ }^{4}$ Department of Paediatrics Inselspital, Bern University Hospital, University of Bern, Bern, Switzerland. ${ }^{5}$ Division of Paediatric Oncology/Haematology, University Children's Hospital Basel, Basel, Switzerland.

Received: 20 January 2020 Accepted: 11 April 2020

Published online: 17 April 2020

\section{References}

1. Wrensch M, Minn Y, Chew T, Bondy M, Berger MS. Epidemiology of primary brain tumors: current concepts and review of the literature. Neurooncology. 2002;4(4):278-99. https://doi.org/10.1088/0952-4746/33/1/1.

2. Wakeford R. The risk of childhood leukaemia following exposure to ionising radiation - a review. J Radiol Prot. 2013;33(1):1-25. https://doi. org/10.1088/0952-4746/33/1/1.

3. Filippini T, Hatch EE, Rothman KJ, Heck JE, Park AS, Crippa A, Orsini N, Vinceti M. Association between outdoor air pollution and childhood leukemia: a systematic review and dose-response meta-analysis. Environ Health Perspect. 2019;127(4):046002. https://doi.org/10.1289/EHP4381.

4. Little MP, Wakeford R, Borrego D, French B, Zablotska LB, Adams MJ, Allodji R, de Vathaire F, Lee C, Brenner AV, et al. Leukaemia and myeloid malignancy among people exposed to low doses (<100 mSv) of ionising radiation during childhood: a pooled analysis of nine historical cohort studies. Lancet Haematol. 2018;5(8):E346-58. https://doi.org/10.1016/ S2352-3026(18)30092-9.

5. Van Maele-Fabry G, Gamet-Payrastre L, Lison D. Residential exposure to pesticides as risk factor for childhood and young adult brain tumors: a systematic review and meta-analysis. Environ Int. 2017;106:69-90. https:// doi.org/10.1016/j.envint.2010.08.016.

6. Waller LA, Carlin BP. Disease mapping. Chapman Hall CRC Handb Mod Stat Methods. 2010;2010:217-43.

7. Wheeler DC. A comparison of spatial clustering and cluster detection techniques for childhood leukemia incidence in Ohio, 1996-2003. Int J Health Geogr. 2007;6:13. https://doi.org/10.1186/1476-072X-6-13.

8. Thompson JA, Carozza SE, Zhu L. An evaluation of spatial and multivariate covariance among childhood cancer histotypes in Texas (United States). Cancer Causes Control. 2007;18(1):105-13. https://doi.org/10.1007/s1055 2-006-0085-8.

9. Manda SO, Feltbower RG, Gilthorpe MS. Investigating spatio-temporal similarities in the epidemiology of childhood leukaemia and diabetes. Eur J Epidemiol. 2009;24(12):743. https://doi.org/10.1007/s10654-009-9391-2. 
10. Cabc F, Mollie A, Bellec S, Guyot-Goubin A, Clavel J, Hemon D. Geographical variations in the incidence of childhood acute leukaemia in France over the period 1990-2004. Eur J Cancer Prev. 2009;18(4):267-79. https:// doi.org/10.1097/CEJ.0b013e32832bf43a.

11. Rainey JJ, Omenah D, Sumba PO, Moormann AM, Rochford R, Wilson ML. Spatial clustering of endemic Burkitt's lymphoma in high-risk regions of Kenya. Int J Cancer. 2007;120(1):121-7. https://doi.org/10.1002/ijc.22179.

12. Lawson A, Rotejanaprasert C. Childhood brain cancer in Florida: a Bayesian Clustering Approach (vol 1, pg 99, 2014). Stat Public Policy. 2015;2(1):93. https://doi.org/10.1080/2330443x.2015.1128192.

13. Ortega-García J, López-Hernández F, Cárceles-Álvarez A, SantiagoRodríguez E, Sánchez A, Bermúdez-Cortes M, Fuster-Soler J. Analysis of small areas of paediatric cancer in the municipality of Murcia (Spain). Anales de Pediatría. 2016;84(3):154-62. https://doi.org/10.1016/j.anped e.2015.04.012

14. Torabi M, Rosychuk RJ. An examination of five spatial disease clustering methodologies for the identification of childhood cancer clusters in Alberta, Canada. Spat Spatio-temporal Epidemiol. 2011;2(4):321-30. https ://doi.org/10.1016/j.sste.2011.10.003.

15. Openshaw S. The modifiable areal unit problem: Geo Books; 1984

16. Wakefield J. Ecologic studies revisited. Annu Rev Public Health. 2008;29:75-90. https://doi.org/10.1146/annurev.publhealth.29.02090 7.090821

17. Konstantinoudis G, Schuhmacher D, Rue H, Spycher BD. Discrete versus continuous domain models for disease mapping. Spat Spatio-temporal Epidemiol. 2020;32:100319. https://doi.org/10.1016/j.sste.2019.100319.

18. Anderson LM, Diwan BA, Fear NT, Roman E. Critical windows of exposure for children's health: cancer in human epidemiological studies and neoplasms in experimental animal models. Environ Health Perspect. 2000;108(Suppl 3):573-94. https://doi.org/10.1289/ehp.00108s3573.

19. Schindler M, Mitter V, Bergstraesser E, Gumy-Pause F, Michel G, Kuehni CE, Swiss Paediatric Oncology G. Death certificate notifications in the Swiss Childhood Cancer Registry: assessing completeness and registration procedures. Swiss Med Wkly. 2015;145:w14225. https://doi.org/10.4414/ smw.2015.14225.

20. Panczak R, Galobardes B, Voorpostel M, Spoerri A, Zwahlen M, Egger M, Swiss National C, Swiss Household P. A Swiss neighbourhood index of socioeconomic position: development and association with mortality. J Epidemiol Community Health. 2012;66(12):1129-36. https://doi. org/10.1136/jech-2011-200699.

21. Spycher BD, Feller M, Roosli M, Ammann RA, Diezi M, Egger M, Kuehni CE. Childhood cancer and residential exposure to highways: a nationwide cohort study. Eur J Epidemiol. 2015;30(12):1263-75. https://doi. org/10.1007/s10654-015-0091-9.

22. Spycher BD, Lupatsch JE, Zwahlen M, Roosli M, Niggli F, Grotzer MA, Rischewski J, Egger M, Kuehni CE, Swiss Pediatric Oncology G, et al. Background ionizing radiation and the risk of childhood cancer: a census-based nationwide cohort study. Environ Health Perspect. 2015;123(6):622-8. https://doi.org/10.1289/ehp.1408548.

23. Møller J, Syversveen AR, Waagepetersen RP. Log Gaussian Cox processes. Scand J Stat. 1998;25(3):451-82. https://doi.org/10.1111/1467-9469.00115.

24. Simpson D, Illian JB, Lindgren F, Sørbye SH, Rue H. Going off grid: computationally efficient inference for log-Gaussian Cox processes. Biometrika. 2016;103(1):49-70. https://doi.org/10.1093/biomet/asv064.

25. Lindgren $F$, Rue $H$, Lindstrom J. An explicit link between Gaussian fields and Gaussian Markov random fields: the stochastic partial differential equation approach. J R Stat Soc B. 2011;73:423-98. https://doi.org/10.111 1/j.1467-9868.2011.00777.x.

26. Simpson D, Rue H, Riebler A, Martins TG, Sørbye SH. Penalising model component complexity: a principled, practical approach to constructing priors. Stat Sci. 2017;32(1):1-28. https://doi.org/10.1214/16-STS576.

27. Rue H, Martino S, Chopin N. Approximate Bayesian inference for latent Gaussian models by using integrated nested Laplace approximations. J R Stat Soc B. 2009;71(2):319-92. https://doi.org/10.111 1/j.1467-9868.2008.00700.x.

28. Rue H, Riebler A, Sørbye SH, Illian JB, Simpson DP, Lindgren FK. Bayesian computing with INLA: a review. Ann Rev Stat Appl. 2017;4:395-421. https ://doi.org/10.1146/annurev-statistics-060116-054045.

29. Gelman A, Goodrich B, Gabry J, Vehtari A. R-squared for Bayesian Regression Models. Am Stat. 2018:1-7. https://doi.org/10.1080/00031 305.2018.1549100.
30. Besag J, York J, Mollié A. A Bayesian image restoration with two applications in spatial statistics. Ann Inst Stat Math. 1991;43:1-59.

31. Riebler A, Sorbye SH, Simpson D, Rue H. An intuitive Bayesian spatial model for disease mapping that accounts for scaling. Stat Methods Med Res. 2016;25(4):1145-65. https://doi.org/10.1177/0962280216660421.

32. Kaatsch P SC. German Childhood Cancer Registry - Report 2015 (19802014). Institute of Medical Biostatistics, Epidemiology and Informatics (IMBEI) at the University Medical Center of the Johannes Gutenberg University Mainz, Germany; 2015.

33. Lacour B, Guyot-Goubin A, Guissou S, Bellec S, Desandes E, Clavel J. Incidence of childhood cancer in France: National Children Cancer Registries, 2000-2004. Eur J Cancer Prev. 2010;19(3):173-81. https://doi.org/10.1097/ cej.0b013e32833876c0.

34. Bellec S, Hemon D, Rudant J, Goubin A, Clavel J. Spatial and space-time clustering of childhood acute leukaemia in France from 1990 to 2000: a nationwide study. Br J Cancer. 2006;94(5):763-70. https://doi.org/10.1038/ sj.bjc.6602980.

35. Armstrong BG. Effect of measurement error on epidemiological studies of environmental and occupational exposures. Occup Environ Med. 1998;55(10):651-6. https://doi.org/10.1136/oem.55.10.651.

36. McNally RJ, Eden TO. An infectious aetiology for childhood acute leukaemia: a review of the evidence. Br J Haematol. 2004;127(3):243-63. https:// doi.org/10.1111/j.1365-2141.2004.05166.x.

37. Goujon S, Kyrimi E, Faure L, Guissou S, Hemon D, Lacour B, Clavel J. Spatial and temporal variations of childhood cancers: literature review and contribution of the French national registry. Cancer Med. 2018. https:// doi.org/10.1002/cam4.1774.

38. Konstantinoudis G, Kreis C, Ammann RA, Niggli F, Kuehni CE, Spycher BD. Spatial clustering of childhood cancers in Switzerland: a nationwide study. Cancer Causes Control. 2018. https://doi.org/10.1007/s1055 2-018-1011-6.

39. Konstantinoudis G, Kreis C, Ammann RA, Niggli F, Kuehni CE, Spycher BD, Swiss Paediatric Oncology G, the Swiss National Cohort Study G. Spatial clustering of childhood leukaemia in Switzerland: a nationwide study. Int J Cancer. 2017;141(7):1324-32. https://doi.org/10.1002/ijc.30832.

40. Filippini T, Heck JE, Malagoli C, Giovane CD, Vinceti M. A review and metaanalysis of outdoor air pollution and risk of childhood leukemia. J Environ Sci Health Part C Environ Carcinog Ecotoxicol Rev. 2015;33(1):36-66. https ://doi.org/10.1080/10590501.2015.1002999.

41. Kendall GM, Little MP, Wakeford R, Bunch KJ, Miles JC, Vincent TJ, Meara $J R$, Murphy MF. A record-based case-control study of natural background radiation and the incidence of childhood leukaemia and other cancers in Great Britain during 1980-2006. Leukemia. 2013;27(1):3-9. https://doi. org/10.1038/leu.2012.151.

42. Demoury C, Marquant F, lelsch G, Goujon S, Debayle C, Faure L, Coste A, Laurent O, Guillevic J, Laurier D, et al. Residential exposure to natural background radiation and risk of childhood acute leukemia in France, 1990-2009. Environ Health Perspect. 2016. https://doi.org/10.1289/EHP29 6.

43. Spix C, Grosche B, Bleher M, Kaatsch P, Scholz-Kreisel P, Blettner M. Background gamma radiation and childhood cancer in Germany: an ecological study. Radiat Environ Biophys. 2017;56(2):127-38. https://doi. org/10.1007/s00411-017-0689-2.

44. Nikkila A, Erme S, Arvela H, Holmgren O, Raitanen J, Lohi O, Auvinen A. Background radiation and childhood leukemia: a nationwide registerbased case-control study. Int J Cancer. 2016;139(9):1975-82. https://doi. org/10.1002/ijc.30264.

45. Adam M, Kuehni CE, Spoerri A, Schmidlin K, Gumy-Pause F, Brazzola P, Probst-Hensch N, Zwahlen M. Socioeconomic status and childhood leukemia incidence in Switzerland. Front Oncol. 2015:5:139. https://doi. org/10.3389/fonc.2015.00139

46. Adam M, Rueegg CS, Schmidlin K, Spoerri A, Niggli F, Grotzer M, von der Weid NX, Egger M, Probst-Hensch N, Zwahlen M, et al. Socioeconomic disparities in childhood cancer survival in Switzerland. Int J Cancer. 2016. https://doi.org/10.1002/ijc.30029.

47. Keegan TJ, Bunch KJ, Vincent TJ, King JC, O'Neill KA, Kendall GM, Maccarthy A, Fear NT, Murphy MF. Case-control study of paternal occupation and social class with risk of childhood central nervous system tumours in Great Britain, 1962-2006. Br J Cancer. 2013;108(9):1907-14. https://doi. org/10.1038/bjc.2013.171. 
48. Ramis R, Tamayo-Uria I, Gomez-Barroso D, Lopez-Abente G, Morales-Piga A, Pardo Romaguera E, Aragones N, Garcia-Perez J. Risk factors for central nervous system tumors in children: new findings from a case-control study. PLOS ONE. 2017;12(2):e0171881. https://doi.org/10.1371/journ al.pone.0171881.

49. McNally RJ, Alston RD, Eden TO, Kelsey AM, Birch JM. Further clues concerning the aetiology of childhood central nervous system tumours. Eur J Cancer. 2004;40(18):2766-72. https://doi.org/10.1016/j.ejca.2004.08.020.

50. Del Risco Kollerud R, Blaasaas KG, Claussen B. Poverty and the risk of leukemia and cancer in the central nervous system in children: a cohort study in a high-income country. Scand J Public Health. 2015;43(7):736-43. https://doi.org/10.1177/1403494815590499.
51. Kreis C, Grotzer M, Hengartner H, Spycher BD, Swiss Paediatric Oncology G, the Swiss National Cohort Study G. Space-time clustering of childhood cancers in Switzerland: a nationwide study. Int J Cancer. 2016;138(9):2127-35. https://doi.org/10.1002/ijc.29955.

\section{Publisher's Note}

Springer Nature remains neutral with regard to jurisdictional claims in published maps and institutional affiliations.
Ready to submit your research? Choose BMC and benefit from:

- fast, convenient online submission

- thorough peer review by experienced researchers in your field

- rapid publication on acceptance

- support for research data, including large and complex data types

- gold Open Access which fosters wider collaboration and increased citations

- maximum visibility for your research: over 100M website views per year

At BMC, research is always in progress.

Learn more biomedcentral.com/submissions 